\title{
A organização regimental dos trabalhos legislativos como instrumento de agenda: uma crítica à luz da teoria do discurso de Habermas
}

\author{
Renato Souza Oliveira Junior \\ renatooliveira@hotmail.com \\ Advogado da União. Mestre em Políticas \\ Públicas (UNICEUB). Coordenador-Geral \\ de Direito Administrativo no Ministério \\ das Relações Exteriores \\ Recebido em 22/03/2011 \\ Aprovado em 23/02/2012
}

\section{Resumo}

A atual organização regimental tornou o aferida pela mediação comunicativa. Assim, Legislativo o órgão mais eficaz e previsível questiona-se a qualidade democrática e isso favoreceu a governabilidade de alguns institutos de algumas práticas no presidencialismo. No entanto, a argumentação sobre a eficiência da produção legislativa não pode constituir parâmetro para aferição da qualidade do processo legislativo. Sob a teoria do discurso de Habermas, o direito encontra legitimidade através aceitabilidade racional da norma, no Congresso Nacional. O resultado é o empobrecimento do debate parlamentar em favor da eficiência legislativa.

\section{Palavras-chave}

Congresso Nacional, organização regimental, teoria do discurso. 


\title{
The regimental organization of the legislatives works as tool of agenda: a criticism under the theory of Habermas discourse
}

\author{
Renato Souza Oliveira Junior
}

Abstract

The current regimental organization did the Legislative a more efficient and predictable organ and that has favored the governance in the presidentialism. But such an argumentation about the efficiency in the legislative production cannot constitute parameter to the check of the quality of legislative process. Under the theory of Habermas discourse, Law finds its legitimacy through the rational acceptability of the rule, checked in the basis of the communicative mediation. Therefore, one questions about the democratic quality of some of the institutes and practices within the Parliament. The result is the impoverishment of parliamentary debate in favor of legislative efficiency.

Key words

Parliament, regimental organization, discourse theory. 


\section{Sumário}

Introdução

1 A organização regimental dos trabalhos legislativos e o papel dos líderes partidários

2 A legitimidade do Direito em Habermas: a teoria do discurso e o caráter procedimental do Direito

3 A teoria do discurso no processo de fundamentação do Direito e a organização regimental dos trabalhos legislativos

Conclusão

Referências Bibliográficas 


\section{Introdução}

É relativamente comum encontrarmos entre os cientistas políticos brasileiros argumentos em defesa do presidencialismo brasileiro, vigente com a Constituição de 1988, ao qual é atribuída a denominação de presidencialismo de coalizão. Para essa corrente, compõe as bases institucionais dessa espécie de sistema de governo a organização dos trabalhos legislativos nos regimentos internos do Senado Federal e da Câmara dos Deputados, sobretudo o papel das lideranças partidárias. Em razão de tal organização, o Legislativo tornou-se órgão mais eficaz e previsível. Favoreceu-se a governabilidade, mesmo no sistema presidencial, sobre o qual a teoria apontaria em sentido contrário, em razão dos conflitos "naturalmente" decorrentes da separação de poderes, os quais acarretariam a paralisia legislativa.

Lastreado as lições de Argelina Figueiredo e Fernando Limongi, ${ }^{1}$ bem como de Fabiano Santos, ${ }^{2}$ pode-se afirmar que o Poder Legislativo brasileiro não constitui órgão naturalmente contrário aos projetos e à agenda do Poder Executivo. Defendem esses autores que, sob o influxo da Constituição de 1988 e da atual organização regimental do Congresso Nacional, haveria uma coordenação entre os ramos Executivo e Legislativo, que implicaria uma complementaridade da agenda de ambos os poderes. ${ }^{3}$

Assim sendo, o modo como os trabalhos legislativos são organizados, com visível concentração de poderes sobre as lideranças partidá rias, possibilita ao Poder Executivo construir e executar uma agenda de governo. O Legislativo, através dos regimentos internos, tornou-se mais eficiente do ponto de vista da produção legislativa, principalmente, daquelas leis afetas ao Governo. A concentração de atribuições nas pessoas dos líderes possibilitou maior disciplina partidária, poder de barganha frente ao Executivo e o uso estratégico do procedimento legislativo, a ponto de se saber como e quando uma proposição pode ser votada e quando deve terminar o processo deliberativo.

A questão que se colocou então diante desses fatos recaiu sobre a qualidade do procedimento deliberativo de formação da opinião e da vontade, materializados em comandos normativos - leis - abstratos e genéricos. Mesmo sendo fator importante para a governabilidade do sistema presidencial, a eficiência na produ-

1 FIGUEIREDO, Argelina Cheibub; LIMONGI, Fernando. Executivo e Legislativo na nova ordem constitucional. $1^{a}$ edição. Rio de Janeiro: Editora FGV, 1999.

2 SANTOS, Fabiano. Partidos e comissões no presidencialismo de coalizão. Dados. Rio de Janeiro, v. 45, n. 2, 2002, p. 237-264.

3 FIGUEIREDO, Argelina Cheibub; LIMONGI, Fernando. Poder de Agenda e Políticas Públicas Substantivas. In: Legislativo Brasileiro em Perspectiva Comparada. Magda Inácio e Lucio Rennó (Orgs.). Belo Horizonte: Editora UFMG, 2009, p. 77-104. 
ção legislativa (ou mesmo apenas a própria existência de uma produção legislativa) não constitui parâmetro de aferição da qualidade do procedimento legislativo, pelo menos não à luz da teoria do discurso de Habermas. Esta pressupõe que o direito encontra legitimidade através aceitabilidade racional da norma, aferida através da mediação comunicativa.

Ora, para além da análise de eficácia, no estudo do presidencialismo brasileiro e das relações interinstitucionais entre Executivo e Legislativo deve ser aferida a qualidade do processo legislativo. Desse estudo, será possível entender as necessidades interinstitucionais em prol da governabilidade, bem como adequá-las ao processo de maior participação e discussão democrática no processo deliberativo das normas e políticas públicas. Daí a correlação entre os instrumentos de agenda, ${ }^{4}$ postos na organização regimental do Legislativo e a teoria do discurso de Habermas.

Nessa seara, o objetivo do presente artigo é questionar a qualidade democrática de alguns institutos e práticas no Congresso Nacional através de uma abordagem habermasiana. Assim, é dada ênfase à organização dos trabalhos legislativos na Câmara dos Deputados, pois é nessa Casa congressual que se inicia o processo de deliberação das proposições do Poder Executivo (inclusive as medidas provisórias) e da maioria da produção legislativa. A abordagem se iniciará com a apresentação de institutos e práticas legislativas no âmbito da Câmara dos Deputados, previstos regimentalmente, mediante consulta à doutrina especializada e ao próprio Regimento Interno das Casas legislativas. Logo em seguida, será apresentada a proposta de legitimidade do direito de Habermas e sua teoria do discurso. Reservou-se tópico especial sobre a teoria do discurso no processo de fundamentação do direito e sua correlação com a organização dos trabalhos legislativos.

Desse modo, passa-se à análise da organização regimental dos trabalhos legislativos, dando-se ênfase ao papel das lideranças partidárias no conjunto de medidas e de práticas para viabilizar a governabilidade do presidencialismo brasileiro.

4 O poder de agenda é a possibilidade do Poder Executivo influir no ritmo dos trabalhos legislativos, proporcionando-o definir o quê, quando e como um projeto de lei será deliberado pelo Parlamento (COX, Gary W.; MCCUBBINS, Mathew D. Setting the Agenda: Responsible Party Government in the U.S. House of Representatives. New York: Cambridge University Press, 2005, p. 19) . Para isso, os presidentes fazem uso de diversos instrumentos de agenda, como seus poderes legislativos constitucionais (dos quais se destacam as medidas provisórias), nomeação em cargos públicos de políticos ou pessoas indicadas pela base aliada, liberação de emendas parlamentares (valores postos no orçamento para execução de políticas públicas) etc. Entre esses instrumentos, incluem-se àqueles dispostos na organização regimental do Congresso Nacional que buscam viabilizar a governabilidade no sistema presidencial de governo. 


\section{A Organização Regimental Dos Trabalhos Legislativos E O Papel Dos Líderes Partidários.}

Entre as bases institucionais do presidencialismo brasileiro do pós- $88,{ }^{5}$ alguns autores acrescentam o papel das lideranças e o comportamento dos partidos no âmbito do Congresso Nacional. ${ }^{6}$ A análise desses temas é indissociável do poder de agenda do Chefe do Executivo, da aprovação e implementação de políticas públicas e da busca por governabilidade ${ }^{7}$ no sistema presidencialista. Nesse ínterim, Fabiano Santos aduz:

A combinação de sistema presidencialista, representação proporcional de lista aberta e sistema parlamentar fragmentado leva o chefe do Executivo, na intenção de implementar sua agenda de políticas públicas, a distribuir pastas ministeriais entre membros dos principais partidos, na esperança de obter em troca o apoio da maioria do Congresso. ${ }^{8}$

No mesmo sentido, Filomeno Moraes salienta a organização do Executivo pátrio, lecionando que:

O Executivo brasileiro organiza o apoio à sua agenda legislativa em bases partidárias, em moldes muito similares àqueles encontrados em regimes parlamentaristas. O Presidente da República distribui as pastas ministeriais com o objetivo de obter o apoio da maioria dos legisladores; partidos que recebem pastas são membros do governo e devem comportar-se como tal no Congresso, votando a favor das iniciativas patrocinadas pelo Executivo.?

5 Pode-se definir presidencialismo brasileiro no pós-88 como presidencialismo de coalizão. Em doutrina, este é entendido como “(...) o sistema presidencial de governo em que a governabilidade se dá pela formação de coalizão parlamentar mais ampla que o partido do Presidente, servindo de apoio às políticas governamentais, o que é refletido na distribuição das pastas ministeriais e no exercício do poder de agenda legislativa pela Presidência da República. A mecânica do presidencialismo de coalizão mitiga a separação de poderes típica do sistema presidencial de governo, afastando, em conseqüência, a inoperância que lhe é vista como característica"(SAMPAIO, Marco Aurélio. Medida provisória, diálogo constitucional e a falácia da usurpação de poderes legislativos pelo Executivo. Revista de Direito do Estado. Rio de Janeiro: Renovar, 2006, n. 4 (outubro/dezembro 2006, p. 124).

- Sampaio, Marco Aurélio. A Medida Provisória no Presidencialismo Brasileiro. São Paulo: Malheiros, 2007.

7 Governabilidade "traduz a aptidão de um Estado determinado realizar os objetivos a que se propõe - a sua missão -, não em abstrato, mas em face de um quadro concreto" (FERREIRA FILHO, Manoel Gonçalves. Constituição e Governabilidade: Ensaios sobre a (in)governabilidade brasileira. São Paulo: Saraiva, 1995, p. 3).

8 SANTOS, Fabiano. Partidos e comissões no presidencialismo de coalizão. Dados. Rio de Janeiro, v. 45, n. 2, 2002, p. 237.

9 MORAES, Filomeno. Executivo e Legislativo no Brasil pós-constituinte. São Paulo em Perspectiva. São Paulo, v. 15, n. 4, Dez. 2001, p. 49. 
O comportamento dos parlamentares e partidos no âmbito do Congresso Nacional, bem como o papel das lideranças partidárias constituem, nessa seara, fatores essenciais para a formação do consenso majoritário e para aprovação e implementação da agenda governativa. ${ }^{10}$ Marcam, portanto, a passagem do "sistema presidencialista faccional para o sistema presidencialista de coalizão racionalizado". ${ }^{11}$ Figueiredo e Limongi alertam:

Legislativos são instituições igualitárias e majoritárias. No Legislativo, os votos dos representantes eleitos pelo povo têm o mesmo peso, independentemente do número de eleitores que os elegeram, do número de mandatos que já exerceram, do partido a que se filiam etc. No entanto, para o desempenho de suas funções, os legislativos desenvolveram padrões organizacionais próprios. Para tanto distribuem de maneira desigual os recursos e direitos parlamentares. ${ }^{12}$

A organização dos trabalhos das Casas que compõem o Legislativo brasileiro, além da Constituição Federal de 1988, leis e resoluções, está prevista em seus respectivos Regimentos Internos. Na Câmara dos Deputados este foi aprovado pela Resolução n. ${ }^{\circ}$ 17/1989. No Senado Federal, o Regimento Interno está disposto na Resolução n. ${ }^{\circ}$ 93/ 1970, editada em conformidade com a Resolução n. ${ }^{\circ}$ 18/1989. Calha, desde já, salientar o óbvio: ambas as Casas detêm autonomia para formulação de seus Regimentos Internos, independentemente de sanção ou de veto presidencial. Ou seja, os trabalhos parlamentares foram organizados nessas Resoluções por "vontade independente e autônoma da maioria do Congresso Nacional". 13

Três institutos existentes atualmente, diretamente relacionadas aos trabalhos legislativos, não compunham a organização do Legislativo no período de 19461964, são eles: (i) o Colégio de Líderes, criado em 1989 como órgão auxiliar da Mesa Diretora da Câmara dos Deputados, para assuntos relacionados ao calendário de

10 Quando se fala em agenda de governo quer-se referir às escolhas e prioridades governamentais no que concerne às políticas públicas. A agenda de governo retrata o momento em que certos problemas sociais são selecionados e incorporados ao projeto de governo e, após a consideração dos diversos interesses envolvidos e a conformação destes em acordos, em decisões políticas (Cf. TORRES, Pedro Medellín. La política de las políticas públicas: propuesta teórica y metodológica para el estúdio de las políticas públicas em países de frágil institucionalidad. Série Políticas Sociales. Santiago Del Chile: Naciones Unidas - CEPAL, 2004, n.o 93, p. 37-38). O "conteúdo da agenda é definido pelo processo político e se refere às preferências dos atores" (FIGUEIREDO, Argelina Cheibub; LIMONGI, Fernando. Poder de Agenda e Políticas Públicas Substantivas. In: Legislativo Brasileiro em Perspectiva Comparada. Magda Inácio e Lucio Rennó (Orgs.). Belo Horizonte: Editora UFMG, 2009, p. 80).

11 SANTOS, Fabiano. Partidos e comissões no presidencialismo de coalizão. Dados. Rio de Janeiro, v. 45, n. 2, 2002, p. 239.

12 FIGUEIREDO, Argelina Cheibub; LIMONGI, Fernando. Executivo e Legislativo na nova ordem constitucional. $1^{a}$ edição. Rio de Janeiro: Editora FGV, 1999, p. 28.

13 SAMPaio, Marco Aurélio. A Medida Provisória no Presidencialismo Brasileiro. São Paulo: Malheiros, 2007, p. 156. 
votações; (ii) as restrições quanto à apresentação de emendas por legisladores individuais, sobretudo no regime de urgência; e (iii) o encaminhamento de votos pelos líderes. ${ }^{14}$

Luís Eduardo Abreu ${ }^{15}$ entende que "o regimento é utilizado para impor obstáculos e 'vender' soluções, ou para consolidar ou fazer valerem posições quaisquer”. Não obstante o Regimento possa ser deturpado vez ou outra, em geral, é elemento que garante ordem à deliberação parlamentar e efetivamente protege a minoria contra a maioria, no mínimo pela previsibilidade de suas normas. Ademais, a maioria de hoje poderá ser a minoria de amanhã, em conhecido movimento pendular próprio das democracias.

Da organização dos trabalhos do Parlamento brasileiro, destaca-se o papel das lideranças partidárias. Os líderes, em razão de uma série de prerrogativas regimentais, controlam os trabalhos legislativos. Isto é, tomados individualmente, os parlamentares quase não têm capacidade de influenciar o curso dos trabalhos. $\mathrm{O}$ foco, entretanto, recairá sobre a Câmara dos Deputados, porque é aí que, em regra, inicia-se a votação dos projetos de lei e das medidas provisórias propostas pelo Chefe do Poder Executivo na busca da formação de sua agenda governativa. Da mesma forma, é na Câmara que se inicia a maioria das proposições legislativas.

Do Regimento Interno da Câmara dos Deputados (RICD), colacionam-se as seguintes prerrogativas dos líderes partidários: (a) indicar os membros à composição da Mesa, conforme o número de cargos que corresponda a cada uma delas, salvo composição diversa resultante de acordo entre as bancadas (art. $8^{\circ}, \mathbb{\Omega} 1^{\circ}$ ); (b) fazer uso da palavra em quase todos os assuntos submetidos à Câmara (art. 10, I); (c) inscrever membros da bancada para o horário destinado às Comunicações Parlamentares (art. 10, II); (c) encaminhar a votação de qualquer proposição sujeita à deliberação do Plenário, para orientar sua bancada (art. 10, IV); (d) registrar os candidatos do Partido ou Bloco Parlamentar para concorrer aos cargos da Mesa (art. 10, V); (e) indicar à Mesa os membros da bancada para compor as Comissões, e, a qualquer tempo, substituí-los (art. 10, VI); (f) representar, para fins de quorum para a iniciativa coletiva das proposições, exigido pela Constituição Federal ou pelo RICD, exclusivamente o número de Deputados de sua legenda partidária ou parlamentar, na data da apresentação da proposição (art. 102, $₫ 3^{\circ}$ ) etc.

Quanto às prerrogativas de indicar e de substituir membros para as Comissões, Argelina Figueiredo e Fernando Limongi lecionam que os líderes parla-

14 SANTOS. Fabiano. Partidos e comissões no presidencialismo de coalizão. Dados. Rio de Janeiro, v. 45, n. 2, 2002, p. 243-244.

15 ABREU, Luiz Eduardo. "A troca das palavras e a troca das coisas. Política e linguagem no Congresso Nacional”. Mana. Rio de Janeiro, v. 11, n. 2, Oct. 2005, p. 334. 
mentares as têm usado recorrentemente, a fim de que os parlamentares não tenham

(...) de votar medidas que desagradem suas bases eleitorais. Essa prática, geralmente considerada por analistas políticos como expressão de uma imperfeição ou fragilidade dos partidos brasileiros, na verdade denota um comportamento partidário eficaz. Ao mesmo tempo em que defende os interesses do partido à custa dos objetivos congressistas de agradar as bases, protege estes membros parlamentares de retaliações eleitorais. ${ }^{16}$

Os líderes partidários também possuem grande influência sobre as votações. Juntamente com o Presidente da Câmara dos Deputados, as lideranças partidárias são responsáveis pelo controle rígido do processo legislativo e pela própria pauta legislativa. "Por força regimental, os líderes partidários controlam a agenda dos trabalhos e assim restringem o campo aberto às estratégias individualistas dos congressistas". ${ }^{17}$

Ainda entre suas atribuições, os líderes poderão requerer urgência, mas somente quando representam um terço do número de Deputados (art. 154, II, do RICD). Urgência é a dispensa de exigências, interstícios ou formalidades regimentais, porém não todas, para que determinada proposição seja de logo considerada, até sua decisão final (art. 152 do RICD). Dessa forma, os líderes, representantes da maioria absoluta dos membros da Câmara dos Deputados poderão requerer que seja automaticamente incluída na Ordem do Dia, para discussão e votação imediata, ainda que iniciada a sessão em que for apresentada, proposição que verse sobre matéria de relevante e inadiável interesse nacional (art. 155 do RICD). Esse procedimento apresenta limitações à atuação parlamentar, principalmente no que concerne à possibilidade de usar a palavra (art. 157, $\int 3^{\circ}$ do RICD) e de apresentar de emendas.

As comissões parlamentares permanentes compõem a organização descentralizada do Poder Legislativo. Essas apresentam dois sentidos: ser o local de decisões especializadas, garantindo qualidade sobre os trabalhos legislativos e ser a rota obrigatória das proposições legislativas, que serão objeto de apreciação do plenário.

Nesse procedimento ordinário, o relator elabora parecer sobre a proposição, que será submetido à comissão. Caso esta aprove o parecer, a proposição poderá ser submetida a plenário. Em caso contrário, ou não havendo sua apreciação na mesma sessão legislativa, a proposição será arquivada. A comissão também poderá

16 FIGUEIREDO, Argelina Cheibub; LIMONGI, Fernando. Poder de agenda na democracia brasileira: desempenho do governo no presidencialismo pluripartidário. In: Reforma Política: Lições da História Recente. $1^{a}$ Edição. Rio de Janeiro: Editora FGV, 2006, p. 257.

17 FIGUEIREDO, Argelina Cheibub; LIMONGI, Fernando. Executivo e Legislativo na nova ordem constitucional. $1^{a}$ edição. Rio de Janeiro: Editora FGV, 1999, p. 76. 
resolver terminativamente sobre projeto de lei desde que adstrito à sua jurisdição (art. 58, §1 ${ }^{\circ}$, I, da Constituição Federal de 1988).

Com o requerimento de urgência, assegura-se a preponderância do plenário como centro das discussões, esvaziando-se as comissões parlamentares. As comissões passam, nessa medida, a ter pouca influência na definição da agenda de trabalhos da Câmara e no resultado legislativo. Como instrumento de agenda a favor do Poder Executivo, "tudo indica que a ação do colégio de lideres, através do pedido de urgência, funciona como garantia de que esses projetos não só serão votados, como o serão no prazo requerido". ${ }^{18}$

Outra situação controlada estrategicamente pelos líderes partidários, referente às deliberações, é a utilização de votações nominais. Na Câmara dos Deputados a votação simbólica é utilizada como método de decisão, salvo nos casos em que se exige quorum qualificado. "O presidente da Mesa conta os votos favoráveis (parlamentares que permanecem sentados) e contrários (os que ficam em pé) e proclama o resultado sem que se registrem votos". ${ }^{19}$ A votação simbólica está prevista no art. 185 do RICD. Haverá votação nominal nos casos em que seja exigido quorum especial de votação (projetos de emendas à Constituição e leis complementares), conforme o art. 186, I, do RICD. Da mesma forma, se houver pedido de verificação de votação, na votação simbólica, apoiado por seis centésimos dos deputados ou líderes que representem esse número, proceder-se-á então à votação através do sistema nominal, nos termos do $\int 3^{\circ}$ do art. 185 do RICD. Mas, o $\int 4^{\circ}$ deste artigo restringe o uso do pedido de verificação de votação, no decurso de menos de uma hora da proclamação do resultado. Não transcorrido período contado do resultado do último pedido de verificação, só será permitida nova verificação por deliberação do Plenário, a requerimento de um décimo dos Deputados, ou de Líderes que representem esse número. Sobre o assunto, salientam Figueiredo e Limongi:

\footnotetext{
Mas mesmo os líderes não podem usar desse direito indiscriminadamente. Para impedir que votações nominais sejam usadas por minorias com vistas à obstrução dos trabalhos, os RIs de ambas as casas prevêem que entre uma e outra votação nominal deve haver um prazo de uma hora. ${ }^{20}$
}

Logo adiante, os autores lecionam como o uso estratégico do pedido de verificação para fins de votação nominal pode se dar:

18 FIGUEIREDO, Argelina Cheibub; LIMONGI, Fernando. Executivo e Legislativo na nova ordem constitucional. 1ª edição. Rio de Janeiro: Editora FGV, 1999, p. 64.

19 FIGUEIREDO, Argelina Cheibub; LIMONGI, Fernando. Executivo e Legislativo na nova ordem constitucional. $1^{a}$ edição. Rio de Janeiro: Editora FGV, 1999, p. 30.

20 FIGUEIREDO, Argelina Cheibub; LIMONGI, Fernando. Executivo e Legislativo na nova ordem constitucional. $1^{\text {a }}$ edição. Rio de Janeiro: Editora FGV, 1999, p. 30. 


\begin{abstract}
Muitas vezes, interessa aos líderes que certas matérias sejam decididas sob o manto protetor do prazo de uma hora que veda nova votação nominal. Por exemplo, há matérias em que interesses específicos estão em jogo e em que, para alguns parlamentares, seria muito custoso seguir a linha partidária. Se essa decisão se der por voto simbólico, o deputado não precisará manifestar-se publicamente sobre a matéria. Da mesma forma, os partidos podem decidir qual matéria trazer a voto nominal com olhos nos custos político e eleitorais que causam aos partidos adversários. ${ }^{21}$
\end{abstract}

No Senado há, ainda, o chamado voto de liderança. De acordo o art. 293, II, do RISF, "o voto dos líderes representará o de seus liderados presentes, permitida a declaração de voto em documento escrito a ser encaminhado à Mesa para publicação”. Este instrumento, a favor das lideranças partidárias no Senado, não está presente no RICD. Contudo, o RI do Senado regulamenta a sessão conjunta do CN nos casos em que o Regimento Comum é omisso. Ou seja, a votação simbólica por liderança tem lugar na apreciação de MPs.

Os líderes partidários, nessa perspectiva, não poderiam ser considerados usurpadores do papel dos demais parlamentares. Afinal, aqueles são eleitos por estes e, como se disse inicialmente, pressupõe-se que os poderes atribuídos às lideranças foram deliberados pelos próprios parlamentares. Tais poderes têm o efeito de reduzir a indisciplina partidária e a tornar o resultado das votações previsível. Essa previsibilidade é fator essencial para manutenção da própria base de apoio ao governo - a coalizão governamental.

Ao optarem por agir descoordenadamente e individualmente, desassociados das lideranças, os parlamentares têm pouco ou nenhum poder de barganha sobre o Poder Executivo. A melhor estratégia, a toda evidência, é a atuação conjunta. Esta é decorrente do reconhecimento de assimetria no poder de barganha entre o Executivo e o Legislativo. Para Fabiano Santos,

O controle do Executivo sobre a iniciativa em assuntos distributivos retirou um instrumento fundamental para que os congressistas mantivessem ou ampliassem sua influência política. Dado esse monopólio, a única fonte de distribuição de benefícios é o próprio Executivo, o que significa que o presidente ganha enorme poder de barganha vis-à-vis os legisladores individuais. Nesse caso, a cooperação com partidos parlamentares é a melhor estratégia para os parlamentares fortalecerem seu poder de barganha diante do chefe do Executivo.

21 FIGUEIREDO, Argelina Cheibub; LIMONGI, Fernando. Executivo e Legislativo na nova ordem constitucional. $1^{a}$ edição. Rio dxe Janeiro: Editora FGV, 1999, p. 31. 
E isso explica por que, em oposição ao que ocorria no regime de 194664, o comportamento de um partido minimamente disciplinado é essencial para os atuais legisladores brasileiros. ${ }^{22}$

Os líderes partidários, portanto, têm importante papel de intermediação de suas bancadas com o Executivo. Funcionam "como mediadores de trocas políticas entre parlamentares e Executivo". ${ }^{23}$ Dentro desse contexto, mas numa outra abordagem, Abreu, ao diferenciar a linguagem institucional (ou "regimental") da linguagem dos bastidores, também trata da importância das lideranças partidárias com relação aos deputados a elas vinculados. Mesmo tendo objetivo diverso do aqui esboçado, retrata como os líderes podem viabilizar o sistema de troca aos parlamentares a eles vinculados da seguinte forma:

O deputado entra na sala com seu líder e ali "abre o jogo", diz exatamente o que precisa e o porquê. Não faz sentido, por exemplo, ir ao confessionário para dizer "minhas bases precisam disso", mas para afirmar que "se não conseguir dinheiro para essa ponte, não vou me reeleger", ou "estou falido por causa da campanha; preciso fazer o presidente de tal órgão público". O papel do líder é aqui fazer a intermediação desses pedidos, "negociá-los" com o Executivo. Por um lado, ele conhece como os parlamentares da sua bancada expressam seus interesses ou necessidades; por outro, ele usa o peso dos votos do partido para "obter" coisas com o Executivo, dentre elas, as "demandas" da bancada. O líder é, portanto, um nó desse sistema de trocas, com uma característica muito particular: ele organiza no mesmo sistema a troca das palavras, a troca das coisas e a troca das palavras pelas coisas. ${ }^{24}$

Para ter força frente ao Executivo, os parlamentares precisam agir conjuntamente. Assim, caso os pedidos sejam atendidos, o grupo deverá ser capaz de dar os votos prometidos. Em caso contrário, isto é, se não forem atendidos, os parlamentares deverão ser capazes de negar apoio ao governo. Assim,

(...) o comportamento coeso em uma legenda comum é do interesse de cada deputado como forma de conferir credibilidade a uma ameaça que, do contrário, não chegará a importunar ator político tão poderoso quanto o residente brasileiro. ${ }^{25}$

Da mesma forma, Filomeno Moraes observa que a disciplina partidária no pós-88 "germina no seio do próprio Congresso" e conclui:

Mesmo admitindo que a legislação eleitoral leve os parlamentares a

22 SANTOS, Fabiano. Partidos e comissões no presidencialismo de coalizão. Dados. Rio de Janeiro, v. 45, n. 2, 2002, p. 246.

23 SAmpaio, Marco Aurélio. A Medida Provisória no Presidencialismo Brasileiro. São Paulo: Malheiros, 2007, p. 154.

24 ABREU, Luiz Eduardo. A troca das palavras e a troca das coisas. Política e linguagem no Congresso Nacional. Mana. Rio de Janeiro, v. 11, n. 2, Oct. 2005, p. 335.

25 SANTOS, Fabiano. Ob. cit., 2002, p. 242 
cultivar uma atitude individualista, deve-se ressaltar que as políticas de cunho distributivista garantidoras desse tipo de conexão eleitoral dependem do acesso à arena decisória. Assim, o controle centralizado sobre a agenda legislativa impede que as estratégias do "voto pessoal" sejam dominantes. O controle da agenda exercido pelos líderes partidários e pelo Executivo reduz a chance de sucesso das iniciativas individuais dos deputados, dado que os líderes são capazes de reduzir suas oportunidades. ${ }^{26}$

Para o Presidente tal sistemática é extremamente vantajosa. O uso de seus poderes legislativos é facilitado, o número de veto players diminui e a identidade das pessoas com quem se tem que negociar é mais simples e rápida. Às lideranças são conferidos diversos poderes a fim de busca a coesão partidária para questões integrantes da agenda governativa, principalmente, quando o líder e seu partido (ou bancada) compõem a coalizão governamental. Os trabalhos legislativos como delineados regimentalmente pelos próprios parlamentares visam, sobretudo, à racionalização do procedimento, a fim de torná-lo mais dinâmico e evitar a paralisia legislativa, adequando o Legislativo pátrio às necessidades do Estado de Bem-Estar Social (Welfare State).

\section{A Legitimidade do Direito em Habermas: A teoria do discurso e o caráter procedimental do Direito}

Jürgen Habermas, em sua obra "Direito e Democracia: entre facticidade e validade", busca reconstruir as bases legitimadoras do direito nas sociedades pósmetafísicas. Haveria aparente tensão na relação aparentemente contraditória entre a facticidade de um sistema jurídico e a validade abstrata das normas no direito positivo. Tal tensão no direito se manifestaria na oposição entre coerção estatal e fundamentação racional, bem como entre positividade e legitimidade; e, nos direitos fundamentais, seria decorrente da dicotomia entre autonomia pública e privada. Esse paradoxo seria resolvido com a proposta da co-originalidade entre os pontos que se encontram em oposição. "A 'cooriginalidade' entre os pontos em tensão decorre do fato de que um é condição de possibilidade para a existência do outro". ${ }^{27}$

Para Habermas seria possível discussão racional no fórum público onde

26 MORAES, Filomeno. Executivo e Legislativo no Brasil pós-constituinte. São Paulo em Perspectiva. São Paulo, v. 15, n. 4, Dez. 2001, p. 49.

27 HERDY, Rachel. Habermas, pragmatismo e direito. Kriterion. Belo Horizonte, v. 50, n. 119, June 2009, p. 54. 
vale a força do melhor argumento. Pela teoria do discurso, o direito extrai sua legitimidade através de processos e pressupostos de comunicação - a serem juridicamente institucionalizados - "os quais permitem levantar a suposição de que os processos de criação $e$ de aplicação do direito levam a resultados racionais". ${ }^{28}$ Assim, legitimidade é definida em Habermas como "aceitabilidade racional" ${ }^{29}$ Segundo REESE-SCHÄFER o princípio do discurso:

A legitimidade do direito não se apóia, portanto, nem exclusivamente no direito do indivíduo (como sugere a variante liberal), nem no estado dos virtuosos do povo soberano (essa seria a variante rousseauniana), mas na mediação comunicativa, no princípio do discurso do direito $(\ldots) .{ }^{30}$

Habermas procura mostrar a origem comum (co-originalidade) entre a autonomia "privada" e "pública", uma vez que os indivíduos devem conceber-se como co-autores do direito ao qual estão submetidos enquanto destinatários. Isto é, como Habermas funda a legitimidade do direito num arranjo comunicativo, "os parceiros do direito", enquanto participantes de discursos racionais, "devem poder examinar se uma norma controvertida encontra ou poderia encontrar o assentimento de todos os possiveis atingidos" ${ }^{31}$

Como se pode constatar, o direito recebe papel central na proposta de Habermas, por ser o meio privilegiado para a institucionalização, através de um sistema de direitos, das condições gerais necessárias à emergência do acordo e da própria legitimidade do direito. ${ }^{32}$ Nesse ínterim, Habermas busca evitar a subordinação do direito positivo a uma norma de direito natural ou à moralidade. Os direitos humanos, mesmo tendo conteúdo moral, uma vez inscritos na prática de autodeterminação democrática dos indivíduos, devem ser interpretados juridicamente. Não obstante, ele não afaste a relação entre o direito e a moral, relação que não é hierárquica, mas mutuamente complementar: "A moral autônoma e o direito positivo, que depende de fundamentação, encontram-se numa relação de comple-

28 HABERMAS, Jürgen. Direito e Democracia: entre facticidade e validade. Volume II. Tradução: Flávio Beno Siebeneichler. Rio de Janeiro: Tempo Brasileiro, 2003b, p. 153.

29 FORST, Rainer. Jürgen Habermas: Facticidade e Validade. Tradução: Geraldo de Carvalho. Revisão: Amadeu Moreira Fontenele Neto. In: Jürgen Habermas, 80 anos: Direito e Democracia. Günter Frankenberg e Luiz Moreira (Orgs.). Rio de Janeiro: Lumen Juris, 2009, p. 184.

30 REESE-SCHÄFER, Walter. Compreender Habermas. Tradução de Vilmar Shneider. $2^{\mathrm{a}}$ edição. Petrópolis: Vozes, 2009, p. 86.

31 HABERMAS, Jürgen. Direito e Democracia: entre facticidade e validade. Volume I. Tradução: Flávio Beno Siebeneichler. Rio de Janeiro: Tempo Brasileiro, 2003a, p. 138.

32 HERDY, Rachel. Habermas, pragmatismo e direito. Kriterion. Belo Horizonte, v. 50, n. 119, June 2009, p. 55. 
mentação recíproca". 33

Todavia, mesmo possuindo pontos em comum, a moral e o direito permanecem distintos, uma vez que a moral pós-tradicional representa apenas uma forma de saber cultural e o direito, por sua vez, adquire obrigatoriedade de nível, também, institucional. Isto é, o direito não é apenas um sistema de símbolos, mas também um sistema de ação. Dessa forma, as normas jurídicas possuem forma própria que as distinguem das normas morais. Proviriam de processos discursivos, nos quais há também, mas não apenas, fundamentos morais, e referem-se ao comportamento externo entre as pessoas umas com as outras. Por isso, independem da motivação, a partir da qual seriam seguidas.

Habermas, então, elabora o princípio do discurso, neutro ao direito e à moral, a partir da seguinte afirmação: "São válidas as normas de ação às quais todos os possíveis atingidos poderiam dar o seu assentimento, na qualidade de participantes de discursos racionais" 34 . E mais, salienta Rachel Herdy,

(...) é preciso que todos os participantes e possíveis afetados possam aceitar as consequências e os efeitos colaterais que resultariam da observação geral da norma para a satisfação do interesse de todos; e que essas consequências e efeitos colaterais resultantes da observância geral da norma sejam preferidos às demais possibilidades alternativas conhecidas para a regulação daquela conduta..$^{35}$

Uma vez institucionalizado sob a forma jurídica, o princípio do discurso assumiria as feições de princípio da democracia.

O princípio da democracia "destina-se a amarrar um procedimento de normatização legitima do direito". Por ele, só "podem pretender validade legítima as leis jurídicas capazes de encontrar o assentimento de todos os parceiros do direito, num processo jurídico de normatização discursiva”. Contudo, tal princípio não deve se limitar a estabelecer um processo legítimo de normatização, "mas também a orientar a produção do próprio medium do direito". ${ }^{36}$ Ou seja:

$\mathrm{Na}$ visão do princípio do discurso, é necessário estabelecer as condições às quais os direitos em geral devem satisfazer para se adequarem à constituição de uma comunidade de direito e possam servir como medium da auto-organização desta comunidade. Por isso, é preciso

33 HABERMAS, Jürgen. Direito e Democracia: entre facticidade e validade. Volume I. Tradução: Flávio Beno Siebeneichler. Rio de Janeiro: Tempo Brasileiro, 2003a, p. 141.

34 HABERMAS, Jürgen. Direito e Democracia: entre facticidade e validade. Volume I. Tradução: Flávio Beno Siebeneichler. Rio de Janeiro: Tempo Brasileiro, 2003a, p. 142.

35 HERDY, Rachel. Habermas, pragmatismo e direito. Kriterion. Belo Horizonte, v. 50, n. 119, June 2009, p. 59.

36 HABERMAS, Jürgen. Direito e Democracia: entre facticidade e validade. Volume I. Tradução: Flávio Beno Siebeneichler. Rio de Janeiro: Tempo Brasileiro, 2003a, p. 145-146. 
criar não somente o sistema dos direitos, mas também a linguagem que permite à comunidade entender-se enquanto associação voluntária de membros do direito iguais e livres. ${ }^{37}$

Assim, o princípio do discurso

\begin{abstract}
...deve assumir - pela via da institucionalização jurídica - a figura de um princípio da democracia, o qual passa a conferir força legitimadora ao processo de normatização. A idéia básica é a seguinte: o princípio da democracia resulta da interligação que existe entre o princípio do discurso e a forma jurídica. Eu vejo esse entrelaçamento como uma gênese lógica de direitos, a qual pode ser reconstruída passo a passo. Ela começa com a aplicação do princípio do discurso ao direito a liberdades subjetivas de ação em geral - constitutivo para a forma jurídica enquanto tal - e termina quando acontece a institucionalização jurídica de condições para um exercício discursivo da autonomia política, a qual pode equipar retroativamente a autonomia privada, inicialmente abstrata, com a forma jurídica. Por isso, o princípio da democracia só pode aparecer como núcleo de um sistema de direitos. A gênese lógica desses direitos forma um processo circular, no qual o código do direito e o mecanismo para a produção de direito legítimo, portanto o princípio da democracia, se constituem de modo co-originário. ${ }^{38}$
\end{abstract}

Nessa seara, Denninger ressalta que a ideia decisiva é a do "entrelaçamento entre o princípio do discurso e forma jurídica", da qual resulta o princípio democrático. Este forma um sistema de direitos que põe autonomia privada e pública numa relação de condição mútua (co-originária), como no caso da relação interna ou da igualdade de origens da soberania popular e dos direitos humanos. ${ }^{39}$

Dessa forma, o direito moderno, nas sociedades contemporâneas, encontra legitimidade com o reconhecimento da co-originalidade entre autonomia privada (direitos humanos) e pública (soberania popular). No modelo habermasiano, há a identidade entre destinatários do direito com seus autores, através de processos e de pressupostos comunicativos de formação democrática da opinião e da vontade, institucionalizados juridicamente, nos quais prevalecem a força do melhor argumento. A perfeita realização desse modelo levaria à tensão entre facticidade e validade a praticamente desaparecer, pois somente entrariam em "vigor aquelas leis que, em um processo de normatização discursiva, encontraram de fato a anuência de todos

37 HABERMAS, Jürgen. Direito e Democracia: entre facticidade e validade. Volume I. Tradução: Flávio Beno Siebeneichler. Rio de Janeiro: Tempo Brasileiro, 2003a, p. 146.

38 HABERMAS, Jürgen. Direito e Democracia: entre facticidade e validade. Volume I. Tradução: Flávio Beno Siebeneichler. Rio de Janeiro: Tempo Brasileiro, 2003a, p. 158.

39 DENNINGER, Erhard. Chances de uma Resolução Pacífica de Conflitos entre Pessoas Livres e Iguais: Sobre a "Utilidade" da Teoria do Discurso no Direito Interno e Internacional. Tradução: Geraldo de Carvalho. Revisão: Amadeu Moreira Fontenele Neto. In: Jürgen Habermas, 80 anos: Direito e Democracia. Günter Frankenberg e Luiz Moreira (Orgs). Rio de Janeiro: Lumen Juris, 2009, p. 46. 
os sujeitos de direito". ${ }^{40}$

Mas, para que o entrelaçamento jurídico entre a autonomia pública e privada mantenha-se no tempo é necessário que o processo da juridificação estenda-se simultaneamente ao poder político. I sto porque o reconhecimento recíproco de direitos precisa da presença do Estado, o qual deve ser também legitimado. Esta é a ideia do Estado de direito para Habermas. Ele próprio sintetiza:

O Estado é necessário como poder de organização, de sanção e de execução, porque os direitos têm que ser implantados, porque uma comunidade de direito necessita de uma jurisdição organizada e de uma força para estabilizar a identidade, e porque a formação da vontade política cria programas que têm que ser implementados. ${ }^{41}$

Não é, simplesmente, que o direito legitime o poder político, mas o direito legitimamente estatuído. Este só pode ser alcançado nas sociedades pós-metafísicas através da "aceitação racional por parte de todos os membros do direito, numa formação discursiva da opinião e da vontade". ${ }^{42}$

O conceito de soberania popular também possui conotação própria com o princípio do discurso. Habermas pretende "conceber a soberania do povo como procedimento da formação discursiva da opinião e da vontade". 43 A soberania nesse contexto não mais é vista como uma mera reunião de cidadãos autônomos facilmente identificáveis. "Ela se retira para os círculos de comunicação de foros e corporações, de certa forma destituídos de sujeito". " Tais foros ou corporações consistem no que Habermas denomina de esfera ou espaço público. Somente nesta forma autônoma, destituída de sujeitos, o poder comunicativamente diluído da soberania popular pode ligar o poder administrativo do aparelho estatal à vontade dos cidadãos. Assim:

40 ALEXY, Robert. Os Direitos Fundamentais e a Democracia no Paradigma Procedimental do Direito de Jürgen Habermas. Tradução: Geraldo de Carvalho. Revisão: Amadeu Moreira Fontenele Neto. In: Jürgen Habermas, 80 anos: Direito e Democracia. Org(s). Günter Frankenberg e Luiz Moreira. Rio de Janeiro: Lumen Juris, 2009, p. 133.

41 HABERMAS, Jürgen. Direito e Democracia: entre facticidade e validade. Volume I. Tradução: Flávio Beno Siebeneichler. Rio de Janeiro: Tempo Brasileiro, 2003a,p. 171.

42 HABERMAS, Jürgen. Direito e Democracia: entre facticidade e validade. Volume I. Tradução: Flávio Beno Siebeneichler. Rio de Janeiro: Tempo Brasileiro, 2003a, p. 172.

43 REESE-SCHÄFER, Walter. Compreender Habermas. Tradução de Vilmar Shneider. $2^{\mathrm{a}}$ edição. Petrópolis: Vozes, 2009, p. 97.

44 HABERMAS, Jürgen. Direito e Democracia: entre facticidade e validade. Volume I. Tradução: Flávio Beno Siebeneichler. Rio de Janeiro: Tempo Brasileiro, 2003a, p. 173. 
Pelo princípio da soberania popular entende-se a exigência de que a legislação expresse a vontade da totalidade dos cidadãos, ou seja, que deixem de ser meramente destinatários do Direito, mas tornem-se seus co-autores. Aqui, através de uma nova concepção de paradigma jurídico, Habermas reconstrói a relação entre a autonomia privada e a autonomia pública, dissociadas, até então, nas concepções liberal e comunitarista. ${ }^{45}$

A autonomia política, nesse contexto, esclarece "por que a produção de um direito legítimo implica a mobilização das liberdades comunicativas dos cidadãos". ${ }^{46}$

Habermas, insatisfeito com a definição de poder comunicativo como "potencial de uma vontade comum formada numa comunicação não coagida" de Hannah Arendt, que seria incapaz de justificar a implementação das leis resultantes dessa vontade, o emprego do poder administrativo e a concorrência pelo acesso ao sistema político, sugere que o direito seja o medium pelo qual o poder comunicativo se transforma em poder administrativo, o que consistiria na outorga de poderes no quadro de permissões legais. ${ }^{47}$

A idéia do Estado de direito pode ser interpretada então como a exigência de ligar o sistema administrativo, comandado pelo código do poder, ao poder comunicativo, estatuidor do direito, e de mantê-lo longe das influências do poder social, portanto da implantação fática de interesses privilegiados. ${ }^{48}$

Destarte, os direitos de participação política demandam a institucionalização dos processos de formação da opinião e da vontade, os quais culminam em resoluções sobre leis e políticas. Naqueles, o princípio do discurso assume especial importância e encerra dois sentidos: (i) o congnitivo, filtrando contribuições e temas, argumentos e informações, de tal modo que os resultados obtidos têm a seu favor a suposição da aceitabilidade racional. Isto é: o procedimento democrático que deve fundamentar a legitimidade do direito. Há também o (ii) sentido prático de produzir relações de entendimento não coagidas, desencadeando a força produtiva da liberdade comunicativa. ${ }^{49}$

CRUZ, Álvaro Ricardo de Souza. Habermas e o Direito Brasileiro. Rio de Janeiro: Lúmen Júris, 2006, p. 163.

46 HABERMAS, Jürgen. Direito e Democracia: entre facticidade e validade. Volume I. Tradução: Flávio Beno Siebeneichler. Rio de Janeiro: Tempo Brasileiro, 2003a, p. 185.

47 HABERMAS, Jürgen. Direito e Democracia: entre facticidade e validade. Volume I. Tradução: Flávio Beno Siebeneichler. Rio de Janeiro: Tempo Brasileiro, 2003a, p. 187-190.

48 HABERMAS, Jürgen. Direito e Democracia: entre facticidade e validade. Volume I. Tradução: Flávio Beno Siebeneichler. Rio de Janeiro: Tempo Brasileiro, 2003a, p. 190.

49 HABERMAS, Jürgen. Direito e Democracia: entre facticidade e validade. Volume I. Tradução: Flávio Beno Siebeneichler. Rio de Janeiro: Tempo Brasileiro, 2003a, p. 190-191. 
Ponto correspondente é o princípio parlamentar, o qual fornece uma saída ao exercício da soberania popular ao retirar da totalidade dos cidadãos à competência legislativa. A composição e o modo de trabalhar dos parlamentos, contudo, devem ser regulamentados sob a lógica da distribuição de tarefas. Todos os aspectos relacionados aos parlamentos, como o modo de escolha, o status dos deputados, o modo de decisão e a organização dos trabalhos levantam questões do princípio do discurso e, por isso, têm que ser reguladas à sua luz, para que "os pressupostos comunicativos necessários para discursos pragmáticos, éticos e morais, de um lado, e as condições de negociações eqüitativas, de outro lado, possam ser preenchidas satisfatoriamente". ${ }^{50}$

O princípio do pluralismo político e a necessidade de complementar a formação da opinião e da vontade parlamentar por meio da formação informal da opinião na esfera pública política, aberta a todos os cidadãos, por sua vez, representam que o "conteúdo do princípio da soberania popular só se esgota através do princípio que garante esferas públicas autônomas e do princípio da concorrência entre os partidos". ${ }^{51}$

O novo conceito de esfera pública apresentado pelo autor alemão é o elemento essencial de integração entre o Estado e a sociedade, capaz de resolver o problema da relação entre a autonomia privada e a pública. Esfera ou espaço público não pode ser entendido como instituição, organização ou sistema, mas como "fenômeno social elementar", uma "rede adequada para a comunicação de conteúdos, tomadas de posição e opiniões". Consiste, portanto, numa "estrutura comunicacional do agir orientado pelo entendimento, a qual tem a ver com o espaço social gerado no agir comunicativo, não com as funções nem com os conteúdos da comunicação cotidiana". ${ }^{2}$

Já a regra da maioria utilizada para decisão nos parlamentos é para Habermas um bom exemplo para regulamentação jurídica dos processos de deliberação. Segundo o autor,

A regra da maioria mantém uma relação interna com a busca da verdade, na medida em que a decisão tomada em maioria forma apenas uma censura numa discussão em andamento, fixando de certa maneira o resultado provisório de uma formação discursiva de opinião. A partir daí, a decisão da maioria tem que surgir sob a premissa de que objetos do conflito foram abordados de maneira qualificada, isto

50 HABERMAS, Jürgen. Direito e Democracia: entre facticidade e validade. Volume I. Tradução: Flávio Beno Siebeneichler. Rio de Janeiro: Tempo Brasileiro, 2003a, p. 213-214.

51 HABERMAS, Jürgen. Direito e Democracia: entre facticidade e validade. Volume I. Tradução: Flávio Beno Siebeneichler. Rio de Janeiro: Tempo Brasileiro, 2003a, p. 214.

52 HABERMAS, Jürgen. Direito e Democracia: entre facticidade e validade. Volume II. Tradução: Flávio Beno Siebeneichler. Rio de Janeiro: Tempo Brasileiro, 2003b, p. 92. 
é, sob pressupostos comunicativos de um discurso correspondente. Somente então pode-se considerar o seu conteúdo como o resultado racionalmente motivado, porém falível, de uma argumentação que foi suspensa em relação às coerções institucionais de decisão - podendo ser retomada em princípio. ${ }^{53}$

As reservas existentes contra decisões da maioria fundam-se numa interpretação habermasiana pela qual a minoria só daria seu consentimento e sua autorização para a maioria sob a condição de ficar assegurada a possibilidade de que ela possa a vir a se tornar, futuramente, a maioria, com base nos melhores argumentos, podendo, nesse contexto, modificar a decisão antes tomada.

De toda forma, as instituições do Estado de direito devem garantir o exercício efetivo da autonomia política de cidadãos socialmente autônomos, a fim de que o poder comunicativo de uma vontade formada racionalmente surja, encontre expressão em programas legais, e aqui se podem incluir as políticas públicas, tenham amplitude social através da aplicação racional, da implementação administrativa de programas legais (execução de políticas públicas, por exemplo) e desenvolva sua força de integração social - através da estabilização de expectativas e da realização de fins coletivos.

Ao elaborar sua teoria da democracia, Habermas não se limita a buscar a legitimidade do direito na perspectiva empirista do observador. Vai além. Sua teoria "pretende demonstrar que as práticas democráticas podem ser legitimadas através de uma descrição empirista na visão dos próprios participantes". ${ }^{54} \mathrm{O}$ ponto nodal para definição de quem são os participantes, ao seu turno, encontra-se na noção de espaço e de esfera pública antes visto.

A criação legítima do direito assume assim a forma procedimental. Demanda condições exigentes, manifestadas através de processos e pressupostos comunicacionais que buscam a formação do melhor argumento. O processo da política deliberativa constitui, assim, "o âmago do processo democrático". ${ }^{55}$ Reese-Schäfer salienta que a teoria da democracia habermasiana "é claramente apresentada com propósito normativo, pois ele pretende desenvolver aqueles procedimentos, em cuja observância uma decisão pode ser considerada, com razão, democrática" ${ }^{56}$

53 HABERMAS, Jürgen. Direito e Democracia: entre facticidade e validade. Volume I. Tradução: Flávio Beno Siebeneichler. Rio de Janeiro: Tempo Brasileiro, 2003a, p. 223-224.

54 HABERMAS, Jürgen. Direito e Democracia: entre facticidade e validade. Volume II. Tradução: Flávio Beno Siebeneichler. Rio de Janeiro: Tempo Brasileiro, 2003b, p. 11.

55 HABERMAS, Jürgen. Direito e Democracia: entre facticidade e validade. Volume II. Tradução: Flávio Beno Siebeneichler. Rio de Janeiro: Tempo Brasileiro, 2003b, p. 18.

56 REESE-SCHÄFER, Walter. Compreender Habermas. Tradução de Vilmar Shneider. $2^{\mathrm{a}}$ edição. Petrópolis: Vozes, 2009, p. 93. 
Nesse ínterim, Habermas utiliza-se de elementos tanto da perspectiva democrática liberal como da republicana, integrando-os no conceito de um procedimento ideal para a deliberação e a tomada de decisão. Do modelo do Estado de direito liberal, ele adota a institucionalização de base constitucional do processo de decisão, que não prescinde do fato de os cidadãos serem suficientemente ativos ou coletivamente capazes da ação. Do modelo republicano, ele adota orientação mais intensa para os processos reais (formais e informais) de formação da opinião e da vontade numa esfera pública. Isso quer dizer que "qualquer encontro que não se limita a contatos de observação mútua, mas que se alimenta da liberdade comunicativa que uns concedem aos outros, movimenta-se num espaço público, constituído através da linguagem". ${ }^{57}$

A teoria do discurso,

Que atribui ao processo democrático maiores conotações normativas do que o modelo liberal, as quais, no entanto, são mais fracas do que as do modelo republicano, assume elementos de ambas as partes, compondo-os de modo novo. $\mathrm{Na}$ linha do republicanismo, ela coloca no centro o processo político da formação da opinião e da vontade, sem porém entender a constituição do Estado de direito como algo secundário; conforme foi mostrado, ela entende os princípios do Estado de direito como uma resposta coerente à pergunta acerca do modo de institucionalização das formas pretensiosas de comunicação de uma formação democrática da opinião e da vontade. Na teoria do discurso, o desabrochar da política deliberativa não depende de uma cidadania capaz de agir coletivamente e sim, da institucionalização dos correspondentes processos e pressupostos comunicacionais, como também do jogo entre deliberações institucionalizadas e opiniões públicas que de formaram de modo informal. ${ }^{58}$

Importante salientar que a "teoria do discurso considera o sistema político como sistema de ação ao lado de outros, não o centro, nem o ápice, muito menos o modelo estrutural da sociedade". ${ }^{59}$ Ao lado sistema político haveria diversas arenas (ou espaços públicos) comunicacionais, onde se daria a formação democrática da opinião e da vontade. O sucesso da comunicação e da formação da opinião e da vontade não se mediria, ao final do procedimento, pela produção da generalidade, mas por critérios formais do surgimento da opinião pública qualificada. Segundo Habermas

57 HABERMAS, Jürgen. Direito e Democracia: entre facticidade e validade. Volume II. Tradução: Flávio Beno Siebeneichler. Rio de Janeiro: Tempo Brasileiro, 2003b, p. 93.

58 HABERMAS, Jürgen. Direito e Democracia: entre facticidade e validade. Volume II. Tradução: Flávio Beno Siebeneichler. Rio de Janeiro: Tempo Brasileiro, 2003b, p. 21.

59 HABERMAS, Jürgen. Direito e Democracia: entre facticidade e validade. Volume II. Tradução: Flávio Beno Siebeneichler. Rio de Janeiro: Tempo Brasileiro, 2003b, p. 25. 
A "qualidade" de uma opinião pública constitui uma grandeza empírica, na medida em que ela se mede por qualidades procedimentais de seu processo de criação. Vista pelo lado normativo, ela fundamenta uma medida para a legitimidade da influência exercida por opiniões públicas sobre o sistema político. ${ }^{60}$

Não se pode, contudo, reduzir a teoria do direito habermasiana à perspectiva formalista. Sua noção de procedimento está conectada aos direitos fundamentais. Esses direitos são conferidos a todos como garantia de participação discursiva na construção substantiva desses próprios direitos, isto é, da elaboração do sistema jurídico. "Logo os direitos fundamentais são simultaneamente condição e conseqüência desse procedimento discursivo". ${ }^{61}$

Entretanto, o próprio Habermas revela certo pessimismo quanto à implementação de seu modelo. Segundo ele, "nenbuma sociedade complexa conseguirá corresponder ao modelo de socialização comunicativa pura, mesmo que sejam dadas condiçôes favoráveis". 62

No próximo tópico será feita uma abordagem habermasiana a alguns mecanismos de formação de agenda de governo numa perspectiva habermasiana, sobretudo quanto ao voto de liderança e ao esvaziamento das comissões e a consequente votação simbólica pelo plenário das casas legislativas.

\section{A teoria do discurso no processo de fundamentação do direito e a organização regimental dos trabalhos legislativos}

O princípio da soberania, na linha do princípio do discurso, exige a transmissão da competência legislativa para a totalidade dos cidadãos. Como isso não é possível, a saída é o princípio parlamentar. O Congresso Nacional insere-se nessa perspectiva. Segundo Habermas,

A composição e o modo de trabalhar dessas corporações parlamentares têm que ser regulamentados, por seu turno, sob pontos de vista da lógica de distribuição de tarefas. Por isso, o modo de escolha, o status dos deputados (imunidade, mandato livre ou não, formação de minorias), bem como o modo de decisão nas corporações (princípio da maioria, leituras repetidas), inclusive a organização do trabalho (formação de comissões), levantam questões de princípios. Estas têm

60 HABERMAS, Jürgen. Direito e Democracia: entre facticidade e validade. Volume II. Tradução: Flávio Beno Siebeneichler. Rio de Janeiro: Tempo Brasileiro, 2003b, p. 94.

${ }^{61}$ CRUZ, Álvaro Ricardo de Souza. Habermas e o Direito Brasileiro. Rio de Janeiro: Lúmen Júris, 2006, p. 168.

62 HABERMAS, Jürgen. Direito e Democracia: entre facticidade e validade. Volume II. Tradução: Flávio Beno Siebeneichler. Rio de Janeiro: Tempo Brasileiro, 2003b, p. 54. 
que ser reguladas à luz do princípio do discurso, de tal modo que os pressupostos comunicativos necessários para discursos pragmáticos, éticos e morais, de um lado, e as condições de negociações eqüitativas, de outro lado, possam ser preenchidas satisfatoriamente. ${ }^{63}$

O Congresso Nacional é a instituição que pode facilmente ser identificada como espaço ou esfera pública no conceito habermasiano. O princípio representativo e o pluralismo político trabalhados por Habermas são marcas características do sistema político brasileiro no pós-88. Da mesma forma, a regra da maioria é o método de decisão utilizado no âmbito das deliberações do Congresso Nacional. As Casas que o compõem - Câmara dos Deputados e Senado Federal -, calha salientar, mesmo sendo Poder Legislativo, ou seja, órgãos constitucionalmente competentes para produzir o Direito positivo, não esgotam o conceito de espaço público comunicacional de formação democrática da opinião e da vontade. Ao Parlamento, contudo, caberia os discursos de fundamentação, no qual as questões morais, ético-políticas e pragmáticas devem ser abordadas. Com Souza Cruz,

(...) o discurso de fundamentação assume um papel central, vez que harmoniza preferências assume um papel central, vez que harmoniza preferências concorrentes e fixa a identidade pessoal/coletiva de uma sociedade, na qual concorrem discursos de auto-entendimento e negociações/barganhas de interesses. Os valores fundamentais de uma sociedade são identificados, ponderados e acomodados entre si. O legislador político constrói essa identidade lançando mão de forma irrestrita de argumentos normativos e pragmáticos, por meio do consenso ou de negociação eqüitativas. ${ }^{64}$

Então, três são as questões que distinguem os diversos tipos de discursos a ser elaborados em processos de legislação: (a) as questões morais, relacionadas a questões universalizáveis, que "exigem a persecução cooperativa de fins coletivos e a garantia de bens coletivos", isto é, "a possibilidade de regular nossa convivência no interesse simétrico de todos"; (b) as questões ético-políticas que têm a ver com a identidade de quem participa do processo argumentativo; e (c) as questões pragmáticas, concernentes aos "meios apropriados para a realização de preferências e fins que já são dados". ${ }^{65}$

A cada um desses questionamentos corresponde uma forma de negociação. Esta, todavia, distingue-se da prática de entendimento através da finalidade. Neste,

63 HABERMAS, Jürgen. Direito e Democracia: entre facticidade e validade. Volume I. Tradução: Flávio Beno Siebeneichler. Rio de Janeiro: Tempo Brasileiro, 2003a, p. 213-214.

${ }^{64}$ CRUZ, Álvaro Ricardo de Souza. Habermas e o Direito Brasileiro. Rio de Janeiro: Lúmen Júris, 2006, p. 193.

65 HABERMAS, Jürgen. Direito e Democracia: entre facticidade e validade. Volume I. Tradução: Flávio Beno Siebeneichler. Rio de Janeiro: Tempo Brasileiro, 2003a, p. 194-203. 
a união é entendida como consenso; naquelas, como pacto. No entendimento, apela-se para a consideração de normas e valores. $\mathrm{Na}$ negociação, para a avaliação de situações de interesses. Os processos de negociação terão lugar nas situações em que não é possível neutralizar as relações de poder, o que é pressuposto nos discursos racionais. ${ }^{66}$

Habermas, ademais, ensina que o caminho do princípio do discurso para garantir um consenso não-coercitivo é indireto, desdobrando-se nos procedimentos que regulamentam as negociações de forma imparcial. O poder de negociação deve ser disciplinado de forma a ser distribuído, ao menos, igualmente entre os partidos. Pois,

Se a negociação de compromissos decorrer conforme procedimentos que garantem a todos interesses iguais chances de participação nas negociações e na influenciação recíproca, bem como na concretização de todos os interesses envolvidos, pode-se alimentar a suposição plausível de que os pactos a que se chegou são conformes à equidade. ${ }^{67}$

A questão, então, seria: a organização dos trabalhos legislativos na nova ordem constitucional busca a decisão pela força do melhor argumento ou o objetivo é a eficiência legislativa, a governabilidade? Nos casos, por exemplo, em que as lideranças partidárias fazem uso estratégico das votações simbólicas, o procedimento tende a proteger o parlamentar, desobrigando-o de se manifestar publicamente. Não se busca o discurso e a formação do melhor argumento. Ademais, seria a organização dos trabalhos legislativos distribuída de forma igualitária entre os partidos políticos? A resposta a essa questão parece negativa já que os partidos maiores e suas respectivas lideranças têm amplos poderes sobre os trabalhos legislativos (a exemplo da indicação de membros para composição da Mesa Diretora, das designações e substituições para as comissões permanentes, dos pedidos de urgência e do uso estratégico das votações nominais).

A seu turno, o esvaziamento das comissões com pedidos de urgência pelos líderes partidários, tem feito estas perderem seu papel de locus para decisões sobre importantes questões políticas para o plenário. As comissões permanentes são órgãos descentralizados e especializados para emissão de juízos completos (ou mais completos) sobre determinada proposição legislativa. Podem, assim, trazer à luz as consequências positivas e negativas da futura norma, a ponto de justificar a preferência por ela às demais possibilidades alternativas. É nisso que consiste o sentido cognitivo do princípio do discurso e a lógica da distribuição de tarefas.

66 HABERMAS, Jürgen. Direito e Democracia: entre facticidade e validade. Volume I. Tradução: Flávio Beno Siebeneichler. Rio de Janeiro: Tempo Brasileiro, 2003a, p. 177-178, 207.

67 HABERMAS, Jürgen. Direito e Democracia: entre facticidade e validade. Volume I. Tradução: Flávio Beno Siebeneichler. Rio de Janeiro: Tempo Brasileiro, 2003a, p. 208. 
A discussão em plenário, em razão da grande quantidade de parlamentares e do número de proposições postas em votação, não comporta digressões sobre todos os efeitos das futuras leis e/ou programas. A organização dos trabalhos legislativos deveria garantir a participação simétrica de todos os membros, assim como exige que os

(...) discursos conduzidos representativamente sejam porosos e sensíveis aos estímulos, temas e contribuições, informações e argumentos fornecidos por uma esfera pública pluralista, próxima à base, estruturada discursivamente, portanto diluída pelo poder. ${ }^{68}$

O autor alemão leva em consideração, na formação de sua concepção de democracia apoiada no princípio do discurso, "a imagem de uma sociedade descentrada, a qual constitui - ao lado da esfera pública - uma arena para a percepscão, a identificação e o tratamento de problemas de toda a sociedade". ${ }^{69}$ Por isso, a ordem política para ser legítima deve passar pelo crivo do "conceito discursivo de democracia", agregado, necessariamente, à consciência da complexidade das sociedades modernas. Ressalta Forst que em Habermas a condição de legitimidade do direito resulta de "um processo legiferante, o qual 'fundamenta a suposição da aceitabilidade racional das normas estatuídas"'. E continua:

Com isso, o processo democrático legislativo se transforma no 'verdadeiro lugar da integração social' (p. 50), o que significa que aqueles indivíduos sujeitos ao direito têm que ter, ao mesmo tempo, a possibilidade e serem exortados a se verem como autores do direito e, assim, como participantes em uma prática política do entendimento. ${ }^{70}$

A mesma perspectiva parece decorrer das lições de Schmitt. Para este autor,

El Parlamento, en la mayor parte de los Estados, no es ya hoy (la Cámara francesa de los Diputados pude ser en algunos casos una excepción mencionable) un lugar de controversia racional donde existe la posibilidad de que una parte de los diputados convenza a la otra y el acuerdo de la Asamblea pública sea el resultado del debate. ${ }^{71}$

A perspectiva empirista não pode ser a base de legitimidade do Direito ora produzido. Para a produção legislativa ser legítima, deve fundar-se em processos e

${ }^{68}$ HABERMAS, Jürgen. Direito e Democracia: entre facticidade e validade. Volume I. Tradução: Flávio Beno Siebeneichler. Rio de Janeiro: Tempo Brasileiro, 2003a, p. 227-228.

${ }^{69}$ HABERMAS, Jürgen. Direito e Democracia: entre facticidade e validade. Volume II. Tradução: Flávio Beno Siebeneichler. Rio de Janeiro: Tempo Brasileiro, 2003b, p. 24.

70 FORST, Rainer. Jürgen Habermas: Facticidade e Validade. Tradução: Geraldo de Carvalho. Revisão: Amadeu Moreira Fontenele Neto. In: Jürgen Habermas, 80 anos: Direito e Democracia. Günter Frankenberg e Luiz Moreira (Orgs.). Rio de Janeiro: Lumen Juris, 2009, p. $180-181$.

${ }^{71}$ SCHMITT, Carl. Teoria de la Constitución. Versão espanhola de Francisco Ayala. Madrid: Alianza, 2006, p. 306. 
pressupostos comunicacionais, institucionalizados juridicamente, que conduzam a aceitabilidade racional de todos os possíveis atingidos. A governabilidade e estabilidade geradas pelo presidencialismo no pós-88 não podem consistir nas justificativas idôneas para sua manutenção como sistema de governo. Para Habermas

\begin{abstract}
Na perspectiva empirista do observador, nem a pretensão de legitimidade do direito, que se comunica ao poder político através da forma do direito, nem a necessidade de legitimação, a ser preenchida através do recurso a determinadas medidas de validade, são descritas na perspectiva dos participantes, ou seja, nesta perspectiva as condições da aceitabilidade do direito e da dominação política transformam-se em condições de aceitação, e as condições de legitimidade, em condições para a estabilidade de uma fé da maioria na legitimidade da dominação. ${ }^{72}$
\end{abstract}

Uma teoria da democracia, delineada normativamente, "pretende demonstrar que as práticas democráticas podem ser legitimadas através de uma descrição empirista na visão dos próprios participantes", ${ }^{73}$ os quais, é importante salientar, não se confundem com os parlamentares. Argelina Cheibub e Fernando Limongi ${ }^{74}$ e Fabiano Santos, ${ }^{75}$ ao defenderem o presidencialismo como sistema de governo e a governabilidade gerada no mesmo através de diversos mecanismos institucionais previstos na Constituição de 1988 e nos Regimentos Internos das Casas do Poder Legislativo, não focam a aceitabilidade racional das normas estatuídas, mas focam o fato próprio de haver produção legislativa.

A qualidade das instituições (e da organização regimental como instrumento de agenda) não deve ser medida quantitativamente, tomando como objeto o número de normas produzidas, mas pela qualidade deliberativa das decisões políticas. Certas práticas e instituições regimentalmente consagradas parecem, contudo, caminhar no sentido de empobrecer o debate público, evitando o surgimento do melhor argumento. "El Parlamento se convierte en una especie de autoridad que decide en deliberación secreta y que anuncia el resultado del acuerdo en forma de votación en una sesión pública...".76

72 HABERMAS, Jürgen. Direito e Democracia: entre facticidade e validade. Volume II. Tradução: Flávio Beno Siebeneichler. Rio de Janeiro: Tempo Brasileiro, 2003b, p. 11.

73 HABERMAS, Jürgen. Direito e Democracia: entre facticidade e validade. Volume II. Tradução: Flávio Beno Siebeneichler. Rio de Janeiro: Tempo Brasileiro, 2003b, p. 11.

74 FIGUEIREDO, Argelina Cheibub; LIMONGI, Fernando. Poder de agenda na democracia brasileira: desempenho do governo no presidencialismo pluripartidário. In: Reforma Política: Lições da História Recente. $1^{a}$ Edição. Rio de Janeiro: Editora FGV, 2006, p. 249-295.

75 SANTOS, Fabiano. Em defesa do presidencialismo de coalizão. In: Reforma Política: Lições da História Recente. $1^{a}$ Edição. Rio de Janeiro: Editora FGV, 2006, p. 281-295.

76 SCHMITT, Carl. Teoria de la Constitución. Versão espanhola de Francisco Ayala. Madrid: Alianza, 2006, p. 307. 


\section{Conclusão}

As práticas e instituições previstas nos Regimentos Internos quanto à organização dos trabalhos legislativos são importantes instrumentos de agenda governativa. A concentração de poderes nas lideranças partidárias e o comportamento mais disciplinado dos parlamentares em relação aos seus partidos têm possibilitado tornar o Congresso Nacional instituição mais previsível e eficiente no pertinente ao processo legislativo.

Todavia, isso não pode ser considerado medida de qualidade dessa organização. Na perspectiva habermasiana, o procedimento legislativo, pelo qual o Direito adquire sua legitimidade, deve basear-se na qualidade deliberativa das discussões. Isso significa que o processo legislativo deve ser aberto a receber todo tipo de influxo interno e externo (considerando-se outros espaços públicos) para formação do melhor argumento e de sua aceitabilidade racional por todos os possíveis atingidos pelo comando normativo. O procedimento posto nos Regimentos aponta no sentido de empobrecimento do debate público em prol da produção legislativa e, assim, da busca por governabilidade.

O próprio Habermas é descrente quanto à perfeita institucionalização do procedimento que propõe, mas isso não significa que se tem que prevalecer a eficácia legislativa em detrimento da qualidade deliberativa. O Congresso Nacional é o locus decisório onde todas as questões (morais, ético-políticas e pragmáticas) devem ser consideradas e sopesadas no processo de formação da opinião e da vontade, no processo de criação e de legitimidade do Direito. Por isso, deve-se buscar tanto a qualidade como a eficiência deliberativa no processo legislativo. 


\section{Referências Bibliográficas}

ABREU, Luiz Eduardo. A troca das palavras e a troca das coisas. Política e linguagem no Congresso Nacional. Mana. Rio de Janeiro, v. 11, n. 2, Oct. 2005, p. 329-356.

ALEXY, Robert. Os Direitos Fundamentais e a Democracia no Paradigma Procedimental do Direito de Jürgen Habermas. Tradução: Geraldo de Carvalho. Revisão: Amadeu Moreira Fontenele Neto. In: Jürgen Habermas, 80 anos: Direito e Democracia. Org(s). Günter Frankenberg e Luiz Moreira. Rio de Janeiro: Lumen Juris, 2009.

COX, Gary W.; MCCUBBINS, Mathew D. Setting the Agenda: Responsible Party Government in the U.S. House of Representatives. New York: Cambridge University Press, 2005.

CRUZ, Álvaro Ricardo de Souza. Habermas e o Direito Brasileiro. Rio de Janeiro: Lúmen Júris, 2006.

DENNINGER, Erhard. Chances de uma Resolução Pacífica de Conflitos entre Pessoas Livres e Iguais: Sobre a "Utilidade" da Teoria do Discurso no Direito Interno e Internacional. Tradução: Geraldo de Carvalho. Revisão: Amadeu Moreira Fontenele Neto. In: Jürgen Habermas, 80 anos: Direito e Democracia. Günter Frankenberg e Luiz Moreira (Orgs). Rio de Janeiro: Lumen Juris, 2009.

FERREIRA FILHO, Manoel Gonçalves. Constituição e Governabilidade: Ensaios sobre a (in) governabilidade brasileira. São Paulo: Saraiva, 1995.

FIGUEIREDO, Argelina Cheibub; LIMONGI, Fernando. Executivo e Legislativo na nova ordem constitucional. $1^{a}$ edição. Rio de Janeiro: Editora FGV, 1999.

- Poder de Agenda e Políticas Públicas Substantivas. In: Legislativo Brasileiro em Perspectiva Comparada. Magda Inácio e Lucio Rennó (Orgs.). Belo Horizonte: Editora UFMG, 2009, p. 77-104.

- Poder de agenda na democracia brasileira: desempenho do governo no presidencialismo

pluripartidário. In: Reforma Política: Lições da História Recente. $1^{\text {a }}$ Edição. Rio de Janeiro: Editora FGV, 2006, p. 249-295.

FORST, Rainer. Jürgen Habermas: Facticidade e Validade. Tradução: Geraldo de Carvalho. Revisão: Amadeu Moreira Fontenele Neto. In: Jürgen Habermas, 80 anos: Direito e Democracia. Günter Frankenberg e Luiz Moreira (Orgs.). Rio de Janeiro: Lumen Juris, 2009.

HABERMAS, Jürgen. Direito e Democracia: entre facticidade e validade. Volume I. Tradução: Flávio Beno Siebeneichler. Rio de Janeiro: Tempo Brasileiro, 2003a.

. Direito e Democracia: entre facticidade e validade. Volume II. Tradução: Flávio Beno

Siebeneichler. Rio de Janeiro: Tempo Brasileiro, 2003b.

HERDY, Rachel. Habermas, pragmatismo e direito. Kriterion. Belo Horizonte, v. 50, n. 119, June 2009.

MORAES, Filomeno. Executivo e Legislativo no Brasil pós-constituinte. São Paulo em Perspectiva. São Paulo, v. 15, n. 4, Dez. 2001.

REESE-SCHÄFER, Walter. Compreender Habermas. Tradução de Vilmar Shneider. $2^{\mathrm{a}}$ edição. Petrópolis: Vozes, 2009.

SAMPAIO, Marco Aurélio. A Medida Provisória no Presidencialismo Brasileiro. São Paulo: Malheiros, 2007.

Medida provisória, diálogo constitucional e a falácia da usurpação de poderes legislativos

pelo Executivo. Revista de Direito do Estado. Rio de Janeiro: Renovar, 2006, n. 4 (outubro/dezembro 2006), p. 107-139.

SANTOS, Fabiano. Em defesa do presidencialismo de coalizão. In: Reforma Política: Lições da História Recente. $1^{\text {a }}$ Edição. Rio de Janeiro: Editora FGV, 2006, p. 281-295.

. Partidos e comissões no presidencialismo de coalizão. Dados. Rio de Janeiro, v. 45, n.

2, 2002, p. 237-264.

SCHMITT, Carl. Teoria de la Constitución. Versão espanhola de Francisco Ayala. Madrid: Alianza, 2006.

TORRES, Pedro Medellín. La política de las políticas públicas: propuesta teórica y metodológica para el estúdio de las políticas públicas em países de frágil institucionalidad. Série Políticas Sociales. Santiago Del Chile: Naciones Unidas - CEPAL, 2004, n. ${ }^{\circ} 93$. 